\title{
Théologiques
}

\section{Une nouvelle équipe à Théologiques}

\section{Jean Duhaime}

Volume 10, numéro 1, printemps 2002

Les animaux dans la conscience humaine

URI : https://id.erudit.org/iderudit/008443ar

DOI : https://doi.org/10.7202/008443ar

Aller au sommaire du numéro

Éditeur(s)

Faculté de théologie de l'Université de Montréal

ISSN

1188-7109 (imprimé)

1492-1413 (numérique)

Découvrir la revue

Citer ce document

Duhaime, J. (2002). Une nouvelle équipe à Théologiques. Théologiques, 10(1),

3-4. https://doi.org/10.7202/008443ar d'utilisation que vous pouvez consulter en ligne.

https://apropos.erudit.org/fr/usagers/politique-dutilisation/ 


\section{Une nouvelle équipe à Théologiques}

Chère lectrice, cher lecteur,

C’est avec joie que nous vous présentons ce numéro de Théologiques ayant pour thème "Les animaux", dont la préparation a été orchestrée par Nicole Laurin, à laquelle j'exprime ici ma vive reconnaissance.

Comme vous pouvez le constater, ce numéro porte la date de 2002 bien qu'il paraisse en 2004. Notre revue a connu quelques retards dus en partie à un changement à la direction. La nouvelle équipe est maintenant bien en place, de même qu'un comité de rédaction élargi à quinze membres provenant de champs disciplinaires variés.

Les prochains numéros se succéderont à un rythme accéléré, ce qui nous permettra d'être à jour assez rapidement. Le numéro 10/2, qui explore les rapports entre psychanalyse et religion, est déjà très avancé. Un numéro double sur le dialogue entre chrétiens et juifs viendra combler l'année 2003 (11/1-2). Deux numéros sont déjà en chantier pour l'année 2004.

La nouvelle direction de la revue s'est aussi penchée sur le budget. Pour assurer l'équilibre de nos opérations, nous avons dû procéder à un rajustement des coûts d'abonnements, qui n'avaient pas été majorés depuis plusieurs années. Nous comptons aussi sur l'appui de la Faculté de théologie de l'Université de Montréal, et nous avons sollicité quelques organismes subventionnaires et donateurs privés. Nous estimons être ainsi en mesure d'assurer la stabilité financière de Théologiques.

La revue mène également une campagne de recrutement d'abonnés pour élargir son réseau de diffusion. Nos lecteurs sont nos meilleurs porte-parole. C'est pourquoi je vous invite à faire connaître la revue autour de vous, auprès de toute personne que son 
approche interdisciplinaire des questions théologiques peut intéresser.

Mon prédécesseur Guy Lapointe a tenu la barre de Théologiques depuis le début, avec une équipe de collègues généreux et enthousiastes. Au nom des artisans actuels de la revue, je les remercie d'avoir fait de Théologiques un outil de réflexion et d'échange particulièrement précieux dans le contexte socioculturel contemporain. Reconnaissants pour tout le travail accompli, nous comptons bien poursuivre ce projet original et l'amener encore plus loin!

Bonne lecture!

Jean Dubaime

Directeur 